\title{
Ice nucleation properties of volcanic ash from Eyjafjallajökull
}

\author{
C. R. Hoyle ${ }^{1,}$, V. Pinti ${ }^{1}$, A. Welti ${ }^{1}$, B. Zobrist ${ }^{1}$, C. Marcolli ${ }^{1}$, B. Luo ${ }^{1}$, Á. Höskuldsson ${ }^{2}$, H. B. Mattsson ${ }^{3}$, O. Stetzer ${ }^{1}$, \\ T. Thorsteinsson ${ }^{2}$, G. Larsen ${ }^{2}$, and T. Peter ${ }^{1}$ \\ ${ }^{1}$ Institute for Atmospheric and Climate Science, ETH Zurich, Zurich, Switzerland \\ ${ }^{2}$ Institute of Earth Sciences, University of Iceland, Reykjavik, Iceland \\ ${ }^{3}$ Institute for Geochemistry and Petrology, ETH Zurich, Zurich, Switzerland \\ *now at: Laboratory of Atmospheric Chemistry, Paul Scherrer Institut, Villigen, Switzerland
}

Received: 10 May 2011 - Published in Atmos. Chem. Phys. Discuss.: 21 June 2011

Revised: 21 September 2011 - Accepted: 22 September 2011 - Published: 27 September 2011

\begin{abstract}
The ice nucleation ability of volcanic ash particles collected close to the Icelandic volcano Eyjafjallajökull during its eruptions in April and May 2010 is investigated experimentally, in the immersion and deposition modes, and applied to atmospheric conditions by comparison with airborne measurements and microphysical model calculations. The number of ash particles which are active as ice nuclei (IN) is strongly temperature dependent, with a very small minority being active in the immersion mode at temperatures of 250-263 K. Average ash particles show only a moderate effect on ice nucleation, by inducing freezing at temperatures between $236 \mathrm{~K}$ and $240 \mathrm{~K}$ (i.e. approximately $3-4 \mathrm{~K}$ higher than temperatures required for homogeneous ice nucleation, measured with the same instrument). By scaling the results to aircraft and lidar measurements of the conditions in the ash plume days down wind of the eruption, and by applying a simple microphysical model, it was found that the IN active in the immersion mode in the range $250-263 \mathrm{~K}$ generally occurred in atmospheric number densities at the lower end of those required to have an impact on ice cloud formation. However, 3-4 K above the homogeneous freezing point, immersion mode IN number densities a few days down wind of the eruption were sufficiently high to have a moderate influence on ice cloud formation. The efficiency of IN in the deposition mode was found to be poor except at very cold conditions $(<238 \mathrm{~K})$, when they reach an efficiency similar to that of mineral dust with the onset of freezing at $10 \%$ supersaturation with respect to ice, and with the frozen fraction nearing its maximum value at a supersaturation $20 \%$. In summary, these investigations suggest volcanic ash particles to have only moderate effects on atmospheric ice formation.
\end{abstract}

Correspondence to: C. R. Hoyle (chris.hoyle@env.ethz.ch)

\section{Introduction}

There is a range of studies in which the influence of active volcanoes on heterogeneous ice nucleation in the atmosphere has been examined. These studies have resulted in varied conclusions, suggesting that volcanoes are a source of good ice nuclei (IN) (e.g., Isono et al., 1959), that volcanoes are not a source of IN (e.g., Schnell and Delany, 1976), or even that background IN can be deactivated as a result of volcanic activity (e.g., Langer et al., 1974).

There are many factors which may affect the results of such investigations, for example, the geology of the volcano, the gases emitted during the eruption, the type of the eruption and phase during which the measurements were made, or the presence of non-volcanic matter in the plume (e.g. vegetation burnt during the eruption). Further, the experimental method used to detect IN and the freezing mechanism investigated in the experiments may lead to differing results.

Elevated IN concentrations were observed with an IN counter during the eruptions of the volcanoes Mihara and Asama in Japan, by Isono et al. (1959). Langer et al. (1974) conducted measurements with an NCAR IN counter on ash collected near an active vent of a Hawaiian volcano, as well as of crushed lava, and smoke from burnt vegetation. They found enhanced IN concentrations during eruption periods, but also deactivation of IN in a gas-rich volcanic cloud. It was later found by Hussain and Saunders (1984) that the membrane filter technique used by Langer et al. (1974) leads to a low bias in IN concentrations, as water is taken up by hygroscopic particles on the filter.

During the M-PACE campaign in Alaska in 2004, Prenni et al. (2009) found enhanced IN concentrations in air which had passed directly over the active Shiveluch volcano in Kamchatka, approximately $80 \mathrm{~h}$ before the measurements, and suggest this may indicate IN activity of volcanic ash.

Published by Copernicus Publications on behalf of the European Geosciences Union. 
However, the mineral composition of the IN also matched that of Asian mineral dust. Ice nucleation via contact and immersion freezing was investigated by Shaw et al. (2005), using individual ash particles with diameters between $100 \mu \mathrm{m}$ and $300 \mu \mathrm{m}$, placed onto or inserted into a single water droplet, leading to freezing temperatures of approximately $251 \mathrm{~K}$ for immersion freezing and $254-255 \mathrm{~K}$ for contact freezing. Fornea et al. (2009) performed immersion freezing and inside-out contact freezing measurements using individual $250 \mu \mathrm{m}$ and $300 \mu \mathrm{m}$ diameter particles of Mount St. Helens volcanic ash, finding contact freezing temperatures of ca. $262 \mathrm{~K}$, with a range from approximately $261 \mathrm{~K}$ to $265 \mathrm{~K}$ between experiments with different particles. However, whether inside-out contact freezing is fully comparable with the outside-in mechanism in the atmosphere remains uncertain. They also found immersion freezing to occur at around $253-257 \mathrm{~K}$. Freezing onsets of between $250 \mathrm{~K}$ and $260 \mathrm{~K}$ are suggested by Durant et al. (2008), for ash particles in the size range $1-1000 \mu \mathrm{m}$, based on a review of literature values, as well as their own single particle measurements. They also tested a few different mineral compositions but found no strong effect of the composition of ash on the nucleation efficiency.

Aerosols collected during the eruption of Mount St. Helens in 1980 were investigated, by Schnell et al. (1982), for several modes of IN activation (contact, deposition, immersion and a combination of immersion and contact freezing). They found that at concentrations of $3000 \mu \mathrm{g} \mathrm{m}^{-3}$, the ash contained only few IN active at temperatures warmer than $262 \mathrm{~K}$, and at concentrations lower than $500 \mu \mathrm{g} \mathrm{m}^{-3}$, the IN activity of the ash was indistinguishable from background levels.

Samples of volcanic particles were collected on filters during several measurement flights by Schnell and Delany (1976). The samples were investigated for condensation and/or deposition freezing in a thermal diffusion chamber, however no enhancement in IN over the atmospheric background was detected. Limited evidence was found to support the hypothesis that volcanic gases deactivate ambient IN. The filter technique used by Schnell and Delany (1976) is the same as that of Langer et al. (1974) and therefore also expected to be subject to a low bias in IN measurements (Hussain and Saunders, 1984).

Here we investigate the ice nucleation characteristics of ash collected during the recent eruption of Eyjafjallajökull on Iceland, an eruption which has attracted substantial attention in the atmospheric science community (e.g. Schumann et al., 2011; Bukowiecki et al., 2011; Wienhold, 2011; Seifert et al., 2011; Bingemer et al., 2011; Steinke et al., 2011). Here we are able to significantly extend the analysis presented in previous studies by examining both the ice nucleation behaviour of the few best ash particles in the sample, as well as the behaviour of the most common ash particles in the sample. This could not be investigated by studies based on experiments using single ash particles. Furthermore, many of our experiments are performed using subsets of the ash sample which contain particles small enough to have substantial atmospheric lifetimes (diameters smaller than approximately $20 \mu \mathrm{m})$.

Bulk freezing experiments were carried out with a differential scanning calorimeter (DSC). Immersion and deposition freezing was investigated with the Zurich ice nucleation chamber (ZINC), and its vertical extension Immersion Mode Cooling Chamber (IMCA), described by Lüönd et al. (2010).

The next section describes the ash samples, instruments and measurement methods used and the results of the experiments are presented and discussed in Sect. 4. Section 5 provides a summary and conclusion.

\section{The ash samples}

Two similar samples of ash from the April 2010 eruption of Eyjafjallajökull on Iceland were analysed. The first of these was collected approximately $58 \mathrm{~km}$ from the eruption, as the ash fell, on the morning of 15 April. This sample was provided by the Institute of Earth Sciences at the University of Iceland, and was named "Sample 15.04.10-2b" by them. For simplicity, we designate it "Ey0". Its composition is expected to be the same as that of the second sample, which was subjected to a more detailed analysis. The second sample, which we name "Ey1", was collected by a television film crew at Seljavellir (approximately $8 \mathrm{~km}$ south of the active vent on 11 May 2010) and is fine grained with a median grain-size of $550 \mu \mathrm{m}$. The sample was collected by using a knife to separate the fresh layer of ash from older layers, as it was deposited on the ground. The grain-size distribution of the ash is similar to that typically produced by volcanic eruptions involving explosive interaction with an external water source, so called phreatomagmatic eruptions (Zimanowski et al., 1997). Furthermore, looking at the surface morphology of individual ash particles from Eyjafjallajökull (i.e. the main vent) it is clear the samples are dominated by blocky, to equant-shaped, particles with overall low vesicularity and many adhered smaller particles (Fig. 1a). These features are also consistent with typical ash particles generated in phreatomagmatic eruptions (Heiken and Wohletz, 1985; Zimanowski et al., 1997; Dellino et al., 2001).

This is in sharp contrast to the ashes produced in the beginning of the eruption (at the Fimmvörduháls vents), in the time before the Ey0 and Ey1 samples were collected. These ash particles are considerably coarser and show cuspate, convexconcave shapes with high vesicularity and smooth outer surfaces characteristic of traditional magmatic fragmentation (Heiken and Wohletz, 1985; Dellino et al., 2001). These initial ashes represent a dry stage of the eruption, in which no melting of ice took place. Phreatomagmatic ashes were first produced, when the eruption locus shifted to the ice-covered Eyjafjallajökull vent. 

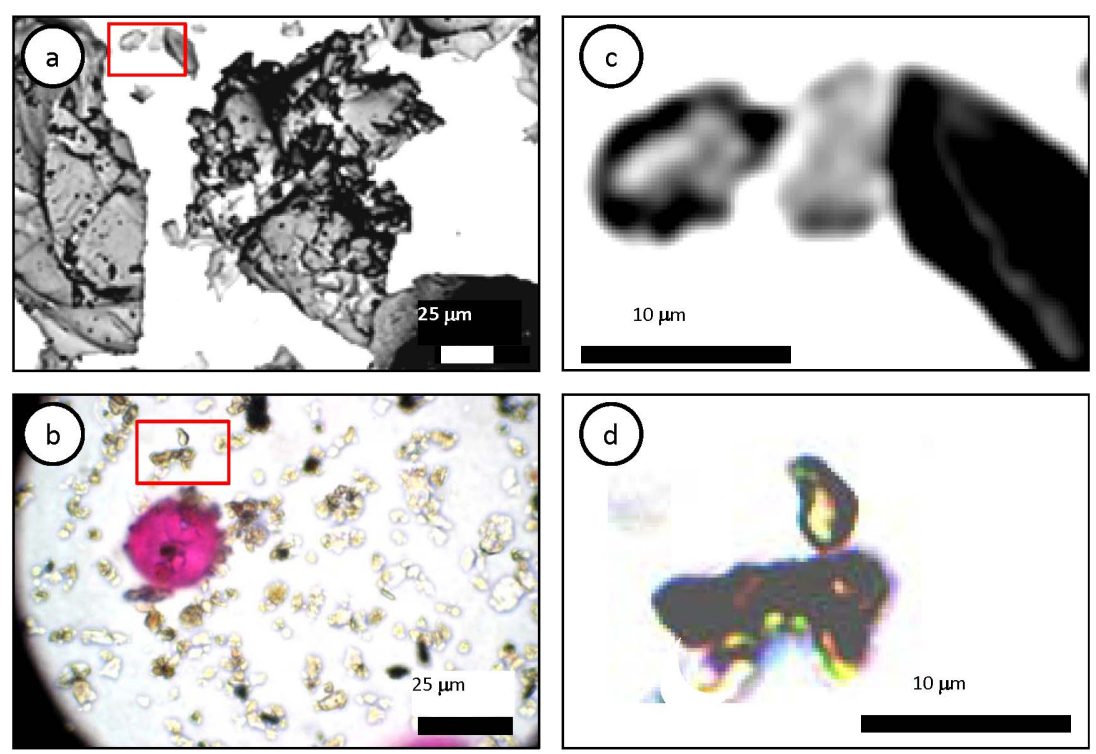

Fig. 1. (a) Scanning electron microscope pictures of the Ey1 sample showing ash particles of 100-200 $\mu \mathrm{m}$ and smaller, collected approximately $8 \mathrm{~km}$ south of the active vent on 11 May 2010. (b) Photo of particles in pollen sampler (hirst-type) in Zurich, Switzerland, about $2500 \mathrm{~km}$ from the volcano, on 19 April. Sampling efficiency in the pollen sampler decreases for particles $<5 \mu$, vanishing below $1 \mu \mathrm{m}$. The large pink particle is a pollen particle, the small irregular particles are mostly volcanic ash particles (photo: Barbara Pietragalla, MeteoSchweiz). Particles in the red boxes are shown on the right (c and $\mathbf{d})$ at larger magnification.

The fragmentation efficiency in phreatomagmatic volcanic eruptions determines how much fine-ash is produced. This is largely controlled by the temperature contrast between the magma and the water, and the efficiency of mixing between the two (and is not dependent on the chemical composition of the magma itself; Zimanowski et al., 1997). The ash samples used in this study can thus be regarded as being representative for material produced in most volcanic eruptions involving explosive interaction with an external water source (i.e., subglacial-, shallow submarine- and lacustrine settings). The significant degree of phreatomagmatic fragmentation, forming fine grained particles, combined with the high eruption plume, lead to the wide spread transport of the ash from Eyjafjallajökull. The large particle in Fig. 1a, owing to its size, will sediment by about $2 \mathrm{~km} \mathrm{~h}^{-1}$, and can therefore not reach large distances from the vent. In contrast, the small particles in Fig. 1a, magnified in Fig. 1c, will sediment only about $10 \mathrm{~m} \mathrm{~h}^{-1}$, and therefore, if carried to sufficient height within the eruption plume, can be transported over continental distances by the atmospheric winds. Similar particles have indeed been found in Central Europe, e.g. see Fig. 1b and d from a pollen sampler in Zurich, Switzerland.

The Ey1 ash sample was only available to us after it had been sieved through a mesh with $40 \mu \mathrm{m}$ holes, however particles larger than $40 \mu \mathrm{m}$ will have a relatively short atmospheric residence time. Aside from this sieving, the Ey1 sample is expected to be similar to the Ey0 sample. The size distribution of ash particles smaller than $300 \mu \mathrm{m}$ in the Ey0 sample was measured with the Sympatec HELOS laser diffrac- tion sensor after dispersion with the Sympatec RODOS dry dispersing unit. The size distribution is shown in Fig. 2.

The size distribution of Ey0 is similar to that of two other ash samples, collected on the 17 and 18 April 2010, approximately $20 \mathrm{~km}$ from the eruption (which are not shown and which we did not examine further in this study). This suggests a relatively high degree of homogeneity in the size distribution of ash at least during the early part of the eruption. Most of the sample mass is accounted for by the largest particles (top and middle panels of Fig. 2). While the percentage of sample mass in particles smaller than a certain diameter decreases almost linearly with decreasing diameter, the percentage of sample mass in each size bin shows peaks for diameters larger than $100 \mu \mathrm{m}$, between 10-40 $\mu \mathrm{m}$, and smaller than $1.8 \mu \mathrm{m}$, the latter due to the inclusion of all particles smaller than $1.8 \mu \mathrm{m}$ in a single size bin. The number of ash particles increases rapidly towards smaller sizes (bottom panel of Fig. 2), with $2 \mu \mathrm{m}$ particles being two orders of magnitude more common than $10 \mu \mathrm{m}$ particles. Particles larger than approximately $50 \mu \mathrm{m}$ in diameter are not likely to have a large scale effect on cloud formation, as they have settling velocities of greater than approximately $0.5 \mathrm{~km} \mathrm{~h}^{-1}$. In comparison, air parcel trajectories show the average transit time between Eyjafjallajökull and central Europe, during April 2010, to be on the order of 2.5 days. 


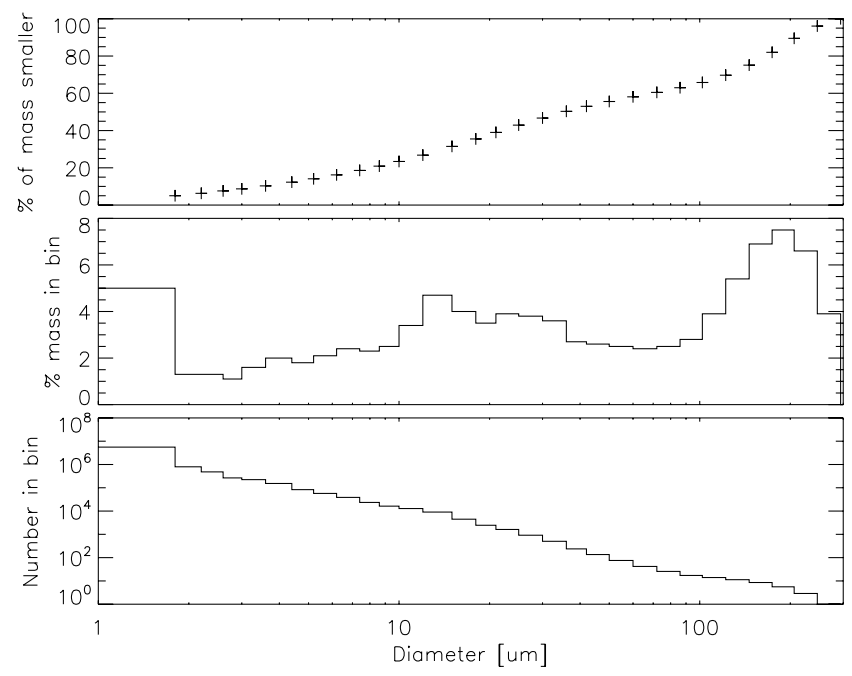

Fig. 2. Size distribution of the Ey0 ash sample collected on 15 April 2010. Top panel: percentage of sample mass made up of particles smaller than the diameter value on the $x$-axis. Centre panel: percentage of sample mass made up by particles in a certain size bin (with bin sizes indicated by the width of the bars; the lowest measured diameter bin, $1.8 \mu \mathrm{m}$ also contains the mass of all smaller particles). Bottom panel: number of particles in each size bin (with particles smaller than $1.8 \mu \mathrm{m}$ diameter counted in the $1.8 \mu \mathrm{m}$ bin. Normalisation: the number of particles is set to unity for the largest size, the number for smaller sizes is then relative to the largest. On the 15 April, there were no particles larger than $300 \mu \mathrm{m}$.

\section{Experimental methods}

\subsection{Differential scanning calorimeter (DSC)}

The bulk freezing experiments were performed with a differential scanning calorimeter (TA instruments Q10), using polychlorotrifluoroethylene (PCTFE) coated sample pans, into which a few milligrams of a suspension of pure water (made with distilled and deionized water, $18.2 \mathrm{M} \Omega$ ) containing the ash was placed with a pipette. The coating ensures a minimal interaction of water and ash in the pan with its surface. Freezing of the suspension sample was detected by the associated latent heat release. The DSC temperature calibration was performed with water, adamantane, cyclohexane, ammonium sulphate and indium, leading to an accuracy of the reported freezing temperatures of $\pm 1.2 \mathrm{~K}$ (Zobrist et al., 2008). The precision in freezing temperature is better than $0.2 \mathrm{~K}$. The onset of the heat flow peak was taken as the ice nucleation temperature, similarly to studies with the same instrument, using emulsions (Zobrist et al., 2006).

\subsection{Deposition nucleation measurements with the ZINC}

The ZINC is a parallel plate continuous flow diffusion chamber. It consists of a nucleation section, where high relative humidity (RH) can be maintained, followed by an evapora- tion section, which is held at ice saturation, where any liquid droplets formed in the nucleation section may evaporate (described in detail by Stetzer et al., 2008). For experiments with the ZINC, the volcanic ash sample was aerosolised using a fluidised bed aerosol generator (TSI Model 3400A), the last stage of which is a cyclone particle separator with a cut off diameter of $3 \mu \mathrm{m}$. The efficiency of the ash particles to act as IN in the deposition mode was investigated by measuring the number of particles which activated as IN and formed ice crystals while passing through ZINC and comparing it to the total particle concentration in the sample flow. The sample stream exiting the evaporation section is passed through an optical particle counter (OPC, CLiMET Cl-3100), where the number of ice particles nucleated can be determined. To unambiguously distinguish ice crystals from ash particles by size in the OPC data, an additional impactor with a cut-off of $1 \mu \mathrm{m}$, was superposed prior to ZINC for the deposition experiments but not for the immersion experiments. This means that the deposition freezing experiments are restricted to particle sizes slightly lower than for the immersion freezing experiments, however, given that the number of particles increases rapidly as size decreases (Fig. 2), both the immersion and deposition freezing experiments examine size ranges where the majority of particles reside.

The measurement and the detection of ice activated fraction are similar to the procedure reported by Welti et al. (2009).

\subsection{Immersion freezing measurements with the IMCA/ZINC}

The aerosol is generated as described in the previous section. For the immersion mode experiments the aerosol is first activated as cloud condensation nuclei $(\mathrm{CCN})$ under warm, supersaturated conditions in IMCA. The design and functional details of IMCA are described by Lüönd et al. (2010). The particles are then fed into the ZINC, where the droplets, each with a single immersed ash particle, are exposed to cold, water saturated conditions. The frozen fractions of the droplets at different temperatures were measured after the nucleation section of ZINC by the depolarisation detector IODE (Ice Optical Detector) described in the work of Nicolet et al. (2010).

\section{Results and discussion}

The two experiments, bulk DSC and IMCA/ZINC single particle measurements, are complementary to each other. Bulk suspension DSC experiments are sensitive to the the best IN, since one nucleation event causes the freezing of the whole sample. Average IN cannot be characterised, as they will be masked by the rare better ones. Conversely, IMCA/ZINC investigates freezing of droplets containing typically only one ash particle, i.e. it is suited to measure the effects of the many 


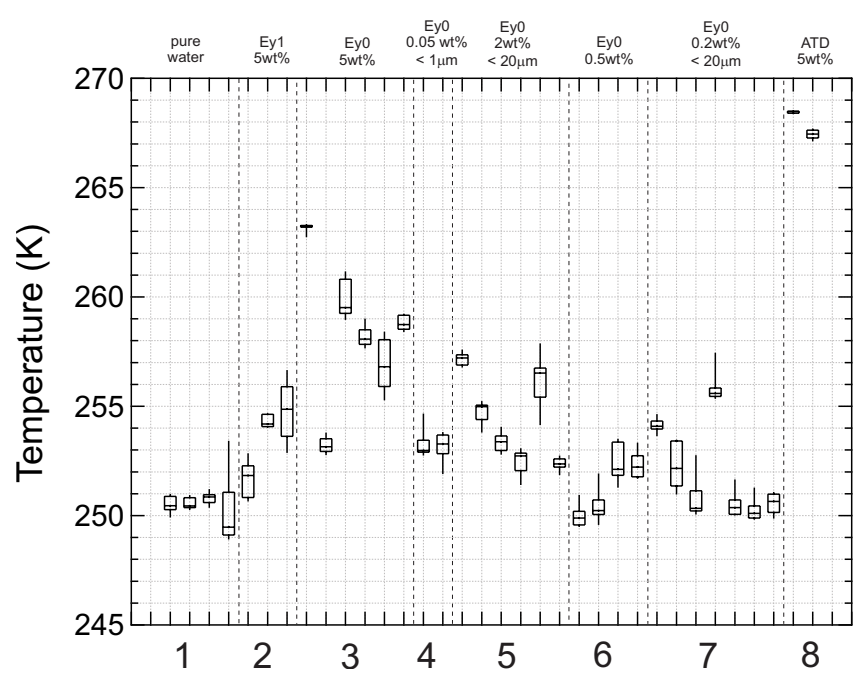

Fig. 3. Bulk freezing temperatures for different suspensions containing ash, and for comparison Arizona test dust. Sets of experimental runs for samples from each suspension are separated by vertical lines. Suspensions: 1 - pure water; 2 - Ey1, $5 \mathrm{wt} \% ; 3$ Ey0, $5 \mathrm{wt} \%$; 4 - Ey0, $0.05 \mathrm{wt} \%$, particles larger than $1 \mu \mathrm{m}$ settled out; 5 - Ey0, $2 \mathrm{wt} \%$, particles larger than $20 \mu \mathrm{m}$ settled out; 6 Ey0, $0.5 \mathrm{wt} \% ; 7$ - Ey0, $0.2 \mathrm{wt} \%$, particles larger than $20 \mu \mathrm{m}$ settled out; 8 - Arizona test dust, $5 \mathrm{wt} \%$. For each experimental run (810 cooling and warming cycles performed with one sample), boxes show median values and upper and lower quartiles, whiskers show extreme values.

average IN, however due to uncertainties in the discrimination of ice from ash particles it is not sensitive to very low frozen fractions (i.e. frozen fractions less than approximately 0.05 for immersion mode, and $1 \times 10^{-4}$ for deposition mode) and will therefore miss the rare best IN. Parallel application of both methods allows us to investigate IN activity over a wide range of temperatures and frozen fractions, although there is a "blind range" of fair IN in moderately high number densities, which are difficult to detect with either of the methods.

\subsection{Bulk DSC experiments}

A series of experiments were run with the bulk freezing configuration described in Sect. 3.1. In bulk experiments, the whole suspension sample freezes when the first ice nucleus is formed, therefore the measurement is sensitive to the best ice nucleus contained in a sample. Up to ten cooling and warming cycles were run for each sample of a suspension, and the resulting freezing temperatures, $T_{\mathrm{f}}$, along with those for pure water, were used to create the box and whisker plots shown in Fig. 3. Each box and whisker plot represents the results obtained from an "experimental run", i.e. the 8-10 cooling and warming cycles performed with a particular sample. The upper and lower boarders of the box are given by the upper and lower quartile, respectively, and the horizontal line in the
Table 1. Several suspensions of the ash were created, and the freezing temperature of different samples of these suspensions were investigated. The names by which the different suspensions are referred to in the text are listed below, along with the details of the suspension: weight percent of ash in the suspension and the approximate largest diameter of ash particles remaining in the suspension after settling. If no settling was carried out, all diameters from the ash sample are assumed to be represented. For the settled samples, the weight percents are the estimated weight percent after settling, with the weight percent of ash in the sample before settling given in brackets.

\begin{tabular}{llcc}
\hline Number & Name & Wt $\%$ & Diameter \\
\hline 1 & Pure water & - & - \\
2 & Ey1 5wt $\%$ & 5 & all \\
3 & Ey0 5 wt $\%$ & 5 & all \\
4 & Ey0 0.05 wt $<1 \mu \mathrm{m}$ & ca. $0.05(5)$ & ca. $<1 \mu \mathrm{m}$ \\
5 & Ey0 2 wt $<20 \mu \mathrm{m}$ & ca. $2(5)$ & ca. $<20 \mu \mathrm{m}$ \\
6 & Ey0 0.5 wt $\%$ & 0.5 & all \\
7 & Ey0 $0.2 \mathrm{wt} \%<20 \mu \mathrm{m}$ & ca. $0.2(0.5)$ & ca. $<20 \mu \mathrm{m}$ \\
8 & ATD & 5 & all \\
\hline
\end{tabular}

middle of the box shows the value of the median. The highest and lowest values in a particular experimental run are shown by the ends of the whiskers. Several experimental runs were made with samples of the same suspension, to test the reproducibility of the results between samples. Each set of experiments is separated by a vertical line in Fig. 3. The details of the different suspensions are given in Table 1. No systematic change in $T_{\mathrm{f}}$ was detected during the individual experimental runs. This shows that the freezing process does not change the quality of the IN. The melting temperature of the samples was also measured, and found not to differ from that of pure water, suggesting that any soluble matter which may have been present on the ash particles did not significantly affect the freezing temperatures.

Despite the utmost care being taken to ensure cleanliness during the sample preparation, minor impurities and interactions between the sample and the walls of the pan in the DSC cannot be avoided. These typically lead to higher nucleation temperatures, between ca. $249 \mathrm{~K}$ and $253.5 \mathrm{~K}$, as can be seen by the temperatures from the pure water freezing experiments. Therefore, ash suspension freezing below ca. $254 \mathrm{~K}$ cannot be firmly attributed to ice nucleation on an ash particle.

Samples of the Ey1 $5 \mathrm{wt} \%$ suspension produced $T_{\mathrm{f}}$ between about $251 \mathrm{~K}$ and $257 \mathrm{~K}$, while the Ey0 $5 \mathrm{wt} \%$ suspension led to $T_{\mathrm{f}}$ as low as ca. $252.5 \mathrm{~K}$ and as high as $263.5 \mathrm{~K}$. These higher freezing temperatures compared with the pure water case show that for these samples and suspension concentrations heterogeneous nucleation on ash surfaces is the dominant nucleation process. Freezing temperatures between $250-260 \mathrm{~K}$ are in agreement with freezing onsets reported by Durant et al. (2008) for bulk freezing experiments 
with volcanic ash samples from different locations. For a particular experimental run, the variation in the $T_{\mathrm{f}}$ was up to 3-4 K reflecting the stochasticity of the freezing process. The much larger spread in $T_{\mathrm{f}}$, among different experimental runs with samples prepared from the same suspension (e.g. $11 \mathrm{~K}$ in the case of the Ey0 $5 \mathrm{wt} \%$ suspension) indicates that there are differences in IN activity between samples taken from the same suspensions. This suggests that there are a few very rare particles, which are significantly better IN than the other ash particles. The smaller variation of the freezing temperature during a particular experimental run suggests that the same few particles are responsible for nucleation throughout that experimental run.

\subsubsection{Experiments with settled or diluted samples}

Further experimental runs were performed using suspensions of Ey0, where gravitational settling was used to achieve different particle size distributions in the suspension. Stokes' law was used to calculate the sedimentation velocity of the different sized ash particles assuming a density of $2.65 \mathrm{~g} \mathrm{~cm}^{-3}$ (Schumann et al., 2011). Accordingly, the suspension was allowed to settle for $2 \mathrm{~h} 30 \mathrm{~min}$ in order to draw off a sample containing only particles smaller than approximately $1 \mu \mathrm{m}$. This value is only approximate as the density of the ash particles varies (some of the particles even floated), however it can still be assumed that the larger particles are excluded from the suspension. In these two experimental runs (column 4 of Fig. 3, suspension Ey0 $0.05 \mathrm{wt} \%<1 \mu \mathrm{m}$ ), $T_{\mathrm{f}}$ is near the upper end of the range of the pure water experimental runs. When the Ey0 $0.5 \mathrm{wt} \%$ suspension was used, $T_{\mathrm{f}}$ decreases to that of pure water. Comparing these $T_{\mathrm{f}}$ with the considerable higher ones of the $5 \mathrm{wt} \%$ suspensions shows that after diluting the suspension by a factor of 10 , samples of the solution generally no longer contain any of the most efficient IN. We can therefore conclude that there were only on the order of 1-10IN present in the $5 \mathrm{wt} \%$ suspensions that caused freezing above ca. $255 \mathrm{~K}$. Using the size distribution shown in Fig. 2, we estimate that around $10^{6}$ particles were present in the samples of $5 \mathrm{wt} \%$ suspension, so that only about one in a million particles causes freezing at such high temperatures.

\subsubsection{Experiments with Arizona test dust}

For comparison, two experimental runs, performed under the same conditions as for the ash, were carried out using samples of a suspension containing $5 \mathrm{wt} \%$ of Arizona test dust (ATD). The median freezing temperatures for the two ATD experimental runs were $267.5 \mathrm{~K}$ and $268.5 \mathrm{~K}$ with ranges of $267.1-267.7 \mathrm{~K}$ and $268.4-268.8 \mathrm{~K}$, respectively. The fact that $T_{\mathrm{f}}$ is so reproducible between the two ATD experimental runs (which used different samples of the same suspension) suggests that, in contrast to the ash, there are very many IN present, which cause freezing at similar temperatures.

\subsubsection{Dependence on ash surface area density}

The surface area of the ash in each experiment using the Ey0 sample was estimated from the mass and size distribution shown in Fig. 2, assuming spherical particles, and a density of $2.65 \mathrm{~g} \mathrm{~cm}^{-3}$. Grouping all the experiments with samples of the same suspension together, the median freezing temperature as a function of ash surface area was plotted (Fig. 4). There is a clear trend of increasing $T_{\mathrm{f}}$ with increasing ash surface, however, the error bars (representing the highest and lowest $T_{\mathrm{f}}$ for a particular suspension) are too large to say if this increase scales only with total surface area, or if larger particles lead to disproportionally higher $T_{\mathrm{f}}$. The $T_{\mathrm{f}}$, for particular surface areas, found in this study are comparable with values published by Shaw et al. (2005), Durant et al. (2008) and Fornea et al. (2009) (coloured symbols in Fig 4). A similar calculation was carried out for ATD. The surface area of ATD in the sample was $1.03 \mathrm{~cm}^{2}$ and the median $T_{\mathrm{f}} 268 \mathrm{~K}$ (not shown). Note that while the wt $\%$ of ATD in the suspension is similar to that for the ash samples, the surface area is far higher. This means that for the DSC experiments, we can not exclude the possibility that the higher $T_{\mathrm{f}}$ found for ATD is related to the higher surface area present in the sample.

The measured freezing temperature for the pure water sample is shown by the light blue circle. The homogeneous nucleation temperature, shown as a light error bar, was calculated as the temperature at which a pure water bulk sample with a volume of $2.5 \times 10^{-9} \mathrm{~m}^{3}$ reaches a nucleation rate of $0.1 \mathrm{~s}^{-1}$. The error bar spans between the $T_{\mathrm{f}}$ calculated using the nucleation rates of Zobrist et al. (2007), at ca. $239 \mathrm{~K}$, and $T_{\mathrm{f}}$ calculated using the parameterisation given by Earle et al. (2010), at ca. $242 \mathrm{~K}$.

Note that classical nucleation theory predicts a considerably weaker increase of freezing temperature with increasing total surface area than the one observed experimentally.

\subsubsection{Atmospheric number densities of best IN}

In situ measurements of the ash plume have recently been published, showing that with a plume age of 1-2 days, an upper limit for the particle size is around $20 \mu \mathrm{m}$ (Schumann et al., 2011). In 1-2 days, particles of this size sediment by $1-2 \mathrm{~km}$, which is a significant fraction of the original plume height, i.e. larger particles will likely have been eliminated. In order to create samples containing only particles smaller than approximately $20 \mu \mathrm{m}$, we again take advantage of the size dependent settling velocities of ash particles in water. To this end, both $5 \mathrm{wt} \%$ and $0.5 \mathrm{wt} \%$ suspensions of the Ey0 ash were prepared, and these suspensions were then allowed to settle for the time required for particles of $20 \mu \mathrm{m}$ and larger to sediment out. Assuming the ash has a density of $2.65 \mathrm{~g} \mathrm{~cm}^{-3}$ the required settling time was calculated to be approximately $57 \mathrm{~s}$ for the $5 \mathrm{wt} \%$ suspension, which had a depth of $2 \mathrm{~cm}$, and $100 \mathrm{~s}$ for the $0.5 \mathrm{wt} \%$ suspension, which had a depth of $3.5 \mathrm{~cm}$. After settling, the 
Table 2. The nucleation temperature range of the best IN in the Ey0 $2 \mathrm{wt} \%<20 \mu \mathrm{m}$ bulk freezing experiments, and the corresponding estimated number density per air volume assuming a single best IN, when the mass of ash in the sample (and therefore the number of ash particles) is scaled to ash mass density observed in the atmosphere.

\begin{tabular}{lccccc}
\hline Location & wt\% & $\begin{array}{c}\text { Ash mass in } \\
\text { DSC sample }\end{array}$ & $\begin{array}{c}\text { Observed mass } \\
\text { density }\end{array}$ & $\begin{array}{c}\text { Freezing temperature } \\
\text { range }\end{array}$ & $\begin{array}{c}\text { IN number } \\
\text { density }\left(\mathrm{cm}^{-3}\right)\end{array}$ \\
\hline${ }^{1}$ Skagerrak & 2.0 & $0.049 \mathrm{mg}$ & $160 \mu \mathrm{g} \mathrm{m}^{-3}$ & $251.4-258.0 \mathrm{~K}$ & $3.3 \times 10^{-6}$ \\
${ }^{1}$ Baltic Sea & 2.0 & $0.049 \mathrm{mg}$ & $7 \mu \mathrm{g} \mathrm{m}^{-3}$ & $251.4-258.0 \mathrm{~K}$ & $1.4 \times 10^{-7}$ \\
${ }^{2}$ Zurich & 2.0 & $0.049 \mathrm{mg}$ & $600 \mu \mathrm{g} \mathrm{m}^{-3}$ & $251.4-258.0 \mathrm{~K}$ & $1.2 \times 10^{-5}$ \\
${ }^{3}$ Biel & 2.0 & $0.049 \mathrm{mg}$ & $320 \mu \mathrm{g} \mathrm{m}^{-3}$ & $251.4-258.0 \mathrm{~K}$ & $6.5 \times 10^{-6}$ \\
\hline
\end{tabular}

${ }^{1}$ Schumann et al. (2011); ${ }^{2}$ Wienhold (2011); ${ }^{3}$ Bukowiecki et al. (2011)

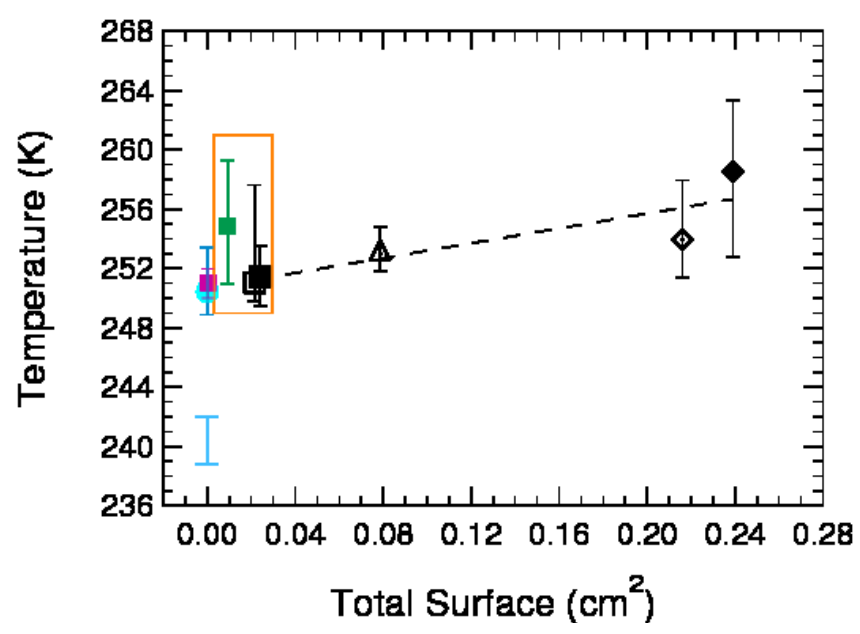

Fig. 4. Bulk freezing temperatures as a function of the surface area of Ey0 ash in the sample. The dashed line shows a linear fit of $T_{\mathrm{f}}$ to the surface area of ash in sample. Pure water is not included in the fit. The black symbols represent the different ash samples: Open square - Ey0 $0.2 \mathrm{wt} \%<20 \mu \mathrm{m}$; Filled square - Ey0 $0.5 \mathrm{wt} \%$; Open triangle - Ey0 $0.05 \mathrm{wt} \%<1 \mu \mathrm{m}$; Open diamond Ey0 $2 \mathrm{wt} \%<20 \mu \mathrm{m}$; Filled diamond - Ey0 $5 \mathrm{wt} \% \mathrm{~g}$. The light blue circle shows the freezing temperature of pure water, bulk sample; Light blue error bar 239-242 K - homogeneous freezing temperature of bulk water sample, calculated using the nucleation rates of Zobrist et al. (2007) and Earle et al. (2010), respectively; The other coloured symbols represent values from the literature: Purple square - Shaw et al. (2005); Green square - Fornea et al. (2009); Area marked by orange rectangle - Durant et al. (2008); The size of the error bars is given by the range of the freezing temperatures for a particular surface area of ash, and not by the precision of the measurements.

estimated suspension concentration was $2 \mathrm{wt} \%$ and $0.2 \mathrm{wt} \%$, respectively, and samples of these suspensions were therefore named Ey0 $2 \mathrm{wt} \%<20 \mu \mathrm{m}$ and Ey0 $0.2 \mathrm{wt} \%<20 \mu \mathrm{m}$. The results for these experiments are also plotted in Fig. 3. There it can be seen that in the Ey0 $2 \mathrm{wt} \%<20 \mu \mathrm{m}$ experimental runs, $T_{\mathrm{f}}$ ranged from ca. $251.5 \mathrm{~K}$ to ca. $258 \mathrm{~K}$, with most of the freezing points obtained being higher than the highest pure water freezing point measured. In the Ey0 $0.2 \mathrm{wt} \%<20 \mu \mathrm{m}$ experimental runs on the other hand, $T_{\mathrm{f}}$ was mostly comparable to that of pure water, except in two cases, where freezing values were up to $255 \mathrm{~K}$ and $257.5 \mathrm{~K}$.

Using the weight fractions for the different particle sizes in Fig. 2, the amount of ash in a sample can now be calculated and related to the amount of ash in an air parcel within the ash plume that was present over Europe. For this analysis, we choose three sets of measurements. The first are aircraft based measurements, using a combination of optical particle counters, reported by Schumann et al. (2011). These measurements were made over the Baltic Sea and Skagerrak, and correspond to the 1-2 day transit times assumed, for which the upper particle size of $20 \mu \mathrm{m}$ was measured. In the analysis presented here, we use the mass densities which they calculated assuming a refractive index of $1.59+0.004 \mathrm{i}$.

The second set of measurements were made over Zurich, during the 17 April 2010, with a Leosphere ALS 450 elastic backscatter lidar operating at $355 \mathrm{~nm}$ wavelength. The extinction to mass conversion factor needed to calculate mass density was found to range between $0.65 \mathrm{~g} \mathrm{~m}^{-2}$ and $1 \mathrm{~g} \mathrm{~m}^{-2}$, from additional simultaneous recordings of the optical backscatter at $455 \mathrm{~nm}$ and $870 \mathrm{~nm}$ by a balloon borne sonde. To this end, statistical modelling of the optical properties was performed, assuming a bimodal size distribution that represented sulphate and ash contributions in the plume. The measurements indicated an upper limit of $600 \mu \mathrm{g} \mathrm{m}^{3}$ for the plume mass density at an altitude of $3 \mathrm{~km}$ over Zurich during 17 April 2010 (Wienhold, 2011).

Finally, we made use of aircraft measurements performed over Biel, Switzerland, on the 18 May 2010. These measurements were made aboard the DIMO research aircraft operated by Metair AG (Switzerland). A Grimm 1.108 optical particle counter was used, and assuming a density of $2.65 \mathrm{~g} \mathrm{~cm}^{-3}$ for the coarse mode particles, the mass density in the ash layer observed on the 18 May 2010 at an altitude of $3500-4500 \mathrm{~m}$ was calculated to be an average of $320 \mu \mathrm{g} \mathrm{m}^{-3}$ (with minimum and maximum values of $200 \mu \mathrm{g} \mathrm{m}^{-3}$ and $520 \mu \mathrm{g} \mathrm{m}^{-3}$, respectively). 


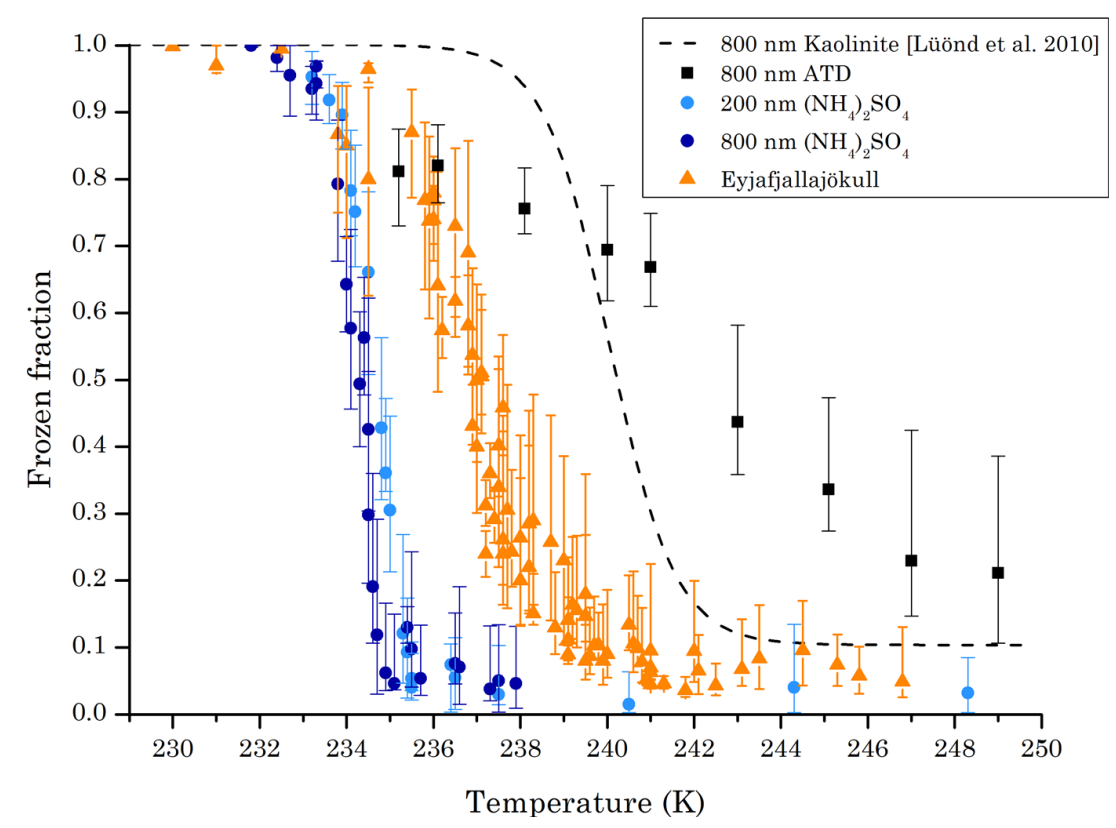

Fig. 5. Immersion freezing of droplets as a function of temperature, from IMCA/ZINC measurements. Orange triangles: fraction of ash particles which nucleated ice, as a function of temperature. Blue points: frozen fraction for homogeneous nucleation of cloud droplets produced by CCN activation of ammonium sulphate particles with dry diameters of $200 \mathrm{~nm}$ (light blue) and $800 \mathrm{~nm}$ (dark blue). For comparison, data for ATD and $800 \mathrm{~nm}$ kaolinite particles are also shown.

To relate the DSC measurements to the atmospheric observations, we take the mass of ash in the sample used in the bulk experiments, and divide by the mass density of the ash particles measured. This gives us the volume of air throughout which the mass of ash in the bulk sample would have been spread. Now, based on the measurements shown in Fig. 3, we can state that within that volume of air, approximately $1-10 \mathrm{IN}$ were present, which would have nucleated ice at the temperature observed in the DSC measurements. The corresponding number densities of ash IN are listed in Table 2.

As an example, the median freezing temperature of the settled Ey0 $2 \mathrm{wt} \%<20 \mu \mathrm{m}$ suspension shown in Table 2 is $254.0 \mathrm{~K}$ (ranging from $251.4 \mathrm{~K}$ to $258 \mathrm{~K}$ ). The mass density of the particles measured in the ash plume over the Skagerrak was $0.16 \mathrm{mg} \mathrm{m}^{-3}$ (Schumann et al., 2011), while the mass of ash in the suspension was $0.049 \mathrm{mg}$. This means the ash in the suspension would have been dispersed throughout approximately $0.3 \mathrm{~m}^{3}$ of air over the Skagerrak, and if we assume that only one single best IN in the suspension was responsible for freezing in this temperature range, the number density of this sort of IN, in the atmosphere, is calculated to be $3.3 \times 10^{-6} \mathrm{~cm}^{-3}$. This value could be up to about a factor of 10 higher, given that there are 1-10 IN with similar properties in most samples of the suspension analysed. Similar calculations were carried out for the Baltic Sea case, and due to the lower mass loading of ash in the observations, the calculated IN number densities are roughly an order of magnitude lower than for the Skagerrak.
The same procedure was repeated with measurements of the ash plume made during the 17 April 2010 over Zurich, Switzerland, and on the 18 May, 2010 over Biel, Switzerland.

The atmospheric implications following from the number densities of best IN in Table 2 and the surface area dependence of $T_{\mathrm{f}}$ in Fig. 4 will be further explored in Sect. 4.4 using trajectory analysis.

\subsection{ZINC immersion freezing results}

Complementary to the bulk freezing experiments discussed above, immersion freezing of the Ey0 sample was investigated with the IMCA/ZINC, between $230 \mathrm{~K}$ and $247 \mathrm{~K}$. The fraction of frozen droplets at each temperature is plotted in Fig. 5 (orange triangles). These measurements were performed on water droplets containing immersed ash particles exposed to supercooled, water saturated conditions. For comparison, homogeneous nucleation experiments were performed, using $200 \mathrm{~nm}$ and $800 \mathrm{~nm}$ (dry diameter) ammonium sulphate particles instead of the ash sample. These particles then activated to cloud droplets, with estimated diameters of $6 \mu \mathrm{m}$, which froze homogeneously between $233 \mathrm{~K}$ and $236 \mathrm{~K}$. The slight difference in freezing temperature between the two different initial sizes of salt particle is due to the freezing point depression caused by the slightly higher concentration of ammonium sulphate in the droplets formed from the $800 \mathrm{~nm}$ particles. Indeed, if the freezing point depression is calculated for both particle sizes, and corrected 


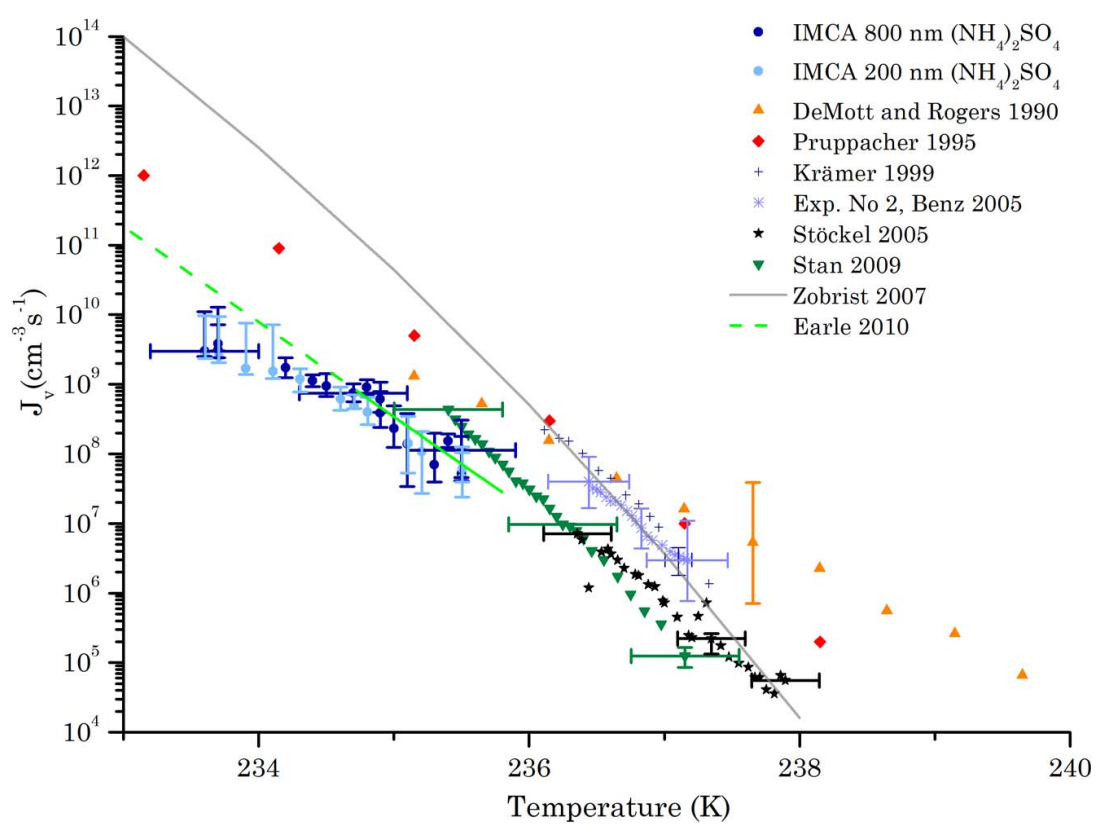

Fig. 6. The homogeneous nucleation rate of water in the temperature range $233 \mathrm{~K}$ to $238 \mathrm{~K}$. The two sets of IMCA/ZINC measurements were made by $\mathrm{CCN}$ activation of $800 \mathrm{~nm}$ and $200 \mathrm{~nm}\left(\mathrm{NH}_{4}\right)_{2} \mathrm{SO}_{4}$ particles, leading to water droplets with estimated diameters of $6 \mu \mathrm{m}$.

for, according to:

$\Delta T=3 \mathrm{M} \cdot 1.86$,

where $\mathrm{M}$ is the molarity of the solution, 3 is the number of ions formed in solution by ammonium sulphate and $1.86 \mathrm{~K} \mathrm{M}^{-1}$ is the freezing point depression for an ideal solution (Seinfeld and Pandis, 2006), the two freezing curves collapse onto a single line. After applying this correction to account for the small remaining freezing point depression of the dissolved salt in the droplets, the resulting homogeneous nucleation rate coefficients between temperatures of $233 \mathrm{~K}$ and $236 \mathrm{~K}$ are plotted in Fig. 6, along with those from other studies. There are few measurements available at the lower end of the temperature range, with the data from Earle et al. (2010) being an extrapolation of measurements made down to approximately $235 \mathrm{~K}$. The slope of the new IMCA/ZINC measurements is slightly less than that of the Earle et al. (2010) data (green line in Fig. 6), and while the data are very similar at 235-235.5 K, where Earle et al. (2010) performed measurements, at lower temperatures the IMCA/ZINC data shows a slower increase of nucleation rate coefficient with decreasing temperature than the extrapolation provided by Earle et al. (2010). The fact that the nucleation rate coefficients derived from IMCA/ZINC measurements match well with previous measurements gives further credibility to the ice formation measurements we present here and ensures that freezing above $236 \mathrm{~K}$ can be attributed to a heterogeneous nucleation process.

Figure 5 shows that heterogeneous freezing on the volcanic ash particles occurs between $236-240 \mathrm{~K}$. There is a
3-4 $\mathrm{K}$ difference between the temperature required to freeze $20 \%$ of the droplets homogeneously vs. heterogeneously on the volcanic ash. The frozen fraction increases more rapidly with decreasing temperature in the homogeneous case, as the nucleation rate is typically a steeper function of temperature for homogeneous than for heterogeneous nucleation, most probably because the variability in the quality of IN in the heterogeneous case leads to a range of $T_{\mathrm{f}}$ (e.g., Marcolli et al., 2007; Zobrist et al., 2007). At the high temperature end of the freezing curves, the frozen fraction of the volcanic ash sample remains at a slightly higher value than the one of the ammonium sulfate droplets. This should not be taken as indication for the presence of ice particles, rather the non-zero measurement is caused by the depolarisation cutoff above which particles are considered to be frozen. Not only the ice particles, but also the ash and dust particles return a slightly depolarised signal, leading to a false frozen particle signal.

The IMCA/ZINC has also previously been used by Lüönd et al. (2010) to investigate the immersion freezing of droplets containing size-selected kaolinite particles. They found frozen fractions of $20 \%$ at approximately $241 \mathrm{~K}$ for $800 \mathrm{~nm}$ particles (dashed black line in Fig. 5), and 239-240 K for $200 \mathrm{~nm}$ particles. The Ey0 sample, on the other hand, resulted in a $20 \%$ frozen fraction at around $238-239 \mathrm{~K}$, showing that the volcanic ash has a lower IN activity than that of similarly sized, or even smaller, mineral dust particles. Furthermore, results for ATD are shown in Fig. 5, displaying an even less steep temperature dependence and higher ice nucleation temperatures than for the ash. 

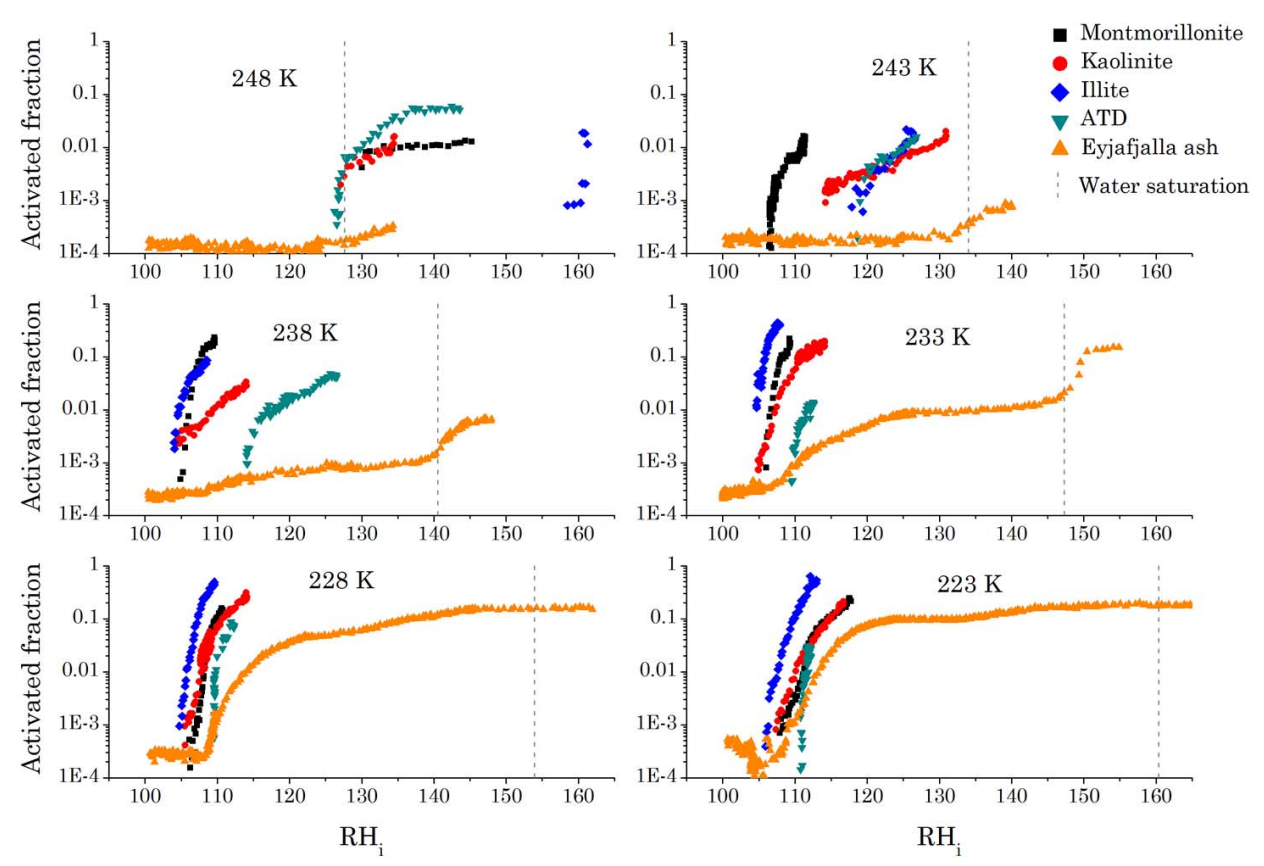

Fig. 7. The fraction of activated (ice coated) ash particles (from the Ey0 ash sample) for deposition mode experiments, as a function of the relative humidity with respect to ice, for different temperatures (orange triangles). Also plotted for comparison: deposition freezing measurements for $800 \mathrm{~nm}$ size-selected mineral dust particles (Welti et al., 2009). The vertical grey line represents water saturation.

The results shown in Fig. 5 demonstrate that the average volcanic ash particle does lead to heterogeneous freezing of cloud droplets, but at temperatures only slightly above the homogeneous freezing threshold. We will examine the atmospheric implications of these average IN using trajectory analysis in Sect. 4.4.

\subsection{ZINC deposition nucleation results}

\subsubsection{ZINC ash and mineral dust deposition mode measurements}

The IN activity of the ash was investigated in the deposition mode, in order to determine if this ice formation pathway could be important in the atmosphere. The fraction of ice coated (i.e. activated) particles for deposition mode experiments with the Ey0 sample is shown in Fig. 7 (orange triangles), as a function of relative humidity with respect to ice $\left(\mathrm{RH}_{\mathrm{ice}}\right)$. Only a very small fraction of the ash particles lead to deposition mode ice nucleation at the warmer temperatures, however the ash becomes increasingly efficient as the temperature decreases. At $248 \mathrm{~K}$ and $243 \mathrm{~K}$ no deposition mode IN activity can be observed before water saturation is reached (vertical dashed grey line). When water saturation is exceeded, a slight increase of the frozen fraction hints at a small fraction of particles showing condensation or immersion freezing after CCN activation. At $238 \mathrm{~K}$ and $233 \mathrm{~K}$, the activated fraction increases continuously as water saturation is approached, and again shows a further stepwise increase when water saturation is exceeded. This indicates that the ash particles, in terms of their average IN behaviour above water saturation, are better immersion mode than deposition mode IN, whereas at lower $\mathrm{RH}_{\text {ice }}$ there is an ability of a small minority of the particles to act as deposition nuclei.

For temperatures of $228 \mathrm{~K}$ and $223 \mathrm{~K}$, the activated fraction reaches almost its maximum value at $\mathrm{RH}_{\text {ice }}=120 \%$, and only increases slightly thereafter, with further increasing humidity. In these two cases, no additional increase in activated fraction is observed as water saturation is reached. The maximum activated fraction at any temperature for this sample is approximately $10 \%$, which is mainly to do with the $12 \mathrm{~s}$ residence time in the ZINC. For longer residence times we would expect a higher activated fraction. Also, it should be noted that, as shown in Fig. 2, there are substantial numbers of particles slightly larger than the $1 \mu \mathrm{m}$ cutoff which it was necessary to apply in the deposition freezing experiments. As one generally expects particles with larger surface area to cause freezing at higher temperatures or lower saturations, these particles may have lead to slightly higher activated fractions, had it been possible to include them. To put these measurements into perspective, we compare with measurements made for mineral dusts under similar experimental conditions (Welti et al., 2009), using size selected, $800 \mathrm{~nm}$ mineral dust particles. Figure 7 shows the results for different clay minerals (montmorillonite, kaolinite, Arizona test dust (ATD) and illite). At $228 \mathrm{~K}$ and $223 \mathrm{~K}$, the threshold $\mathrm{RH}_{\text {ice }}$ of volcanic ash for ice freezing is comparable with the one of ATD and the frozen fraction is slightly smaller, while 
the different clay minerals show a lower threshold $\mathrm{RH}_{\mathrm{ice}}$ and a higher frozen fraction than the volcanic ash. However, the IN efficiency of the volcanic ash strongly deteriorates with increasing temperatures turning it into an overall poor IN compared to the mineral dusts.

Note that the ZINC deposition mode experiment shows by far a higher sensitivity to low fractions of frozen particles than the ZINC/IMCA immersion mode experiments. This is due to the different detection methods used in the experimental set up. Taking into account the different detection limits depending on measurement techniques there is in fact no disagreement between freezing temperatures found in bulk DSC, ZINC/IMCA water droplet and ZINC deposition mode freezing measurements exceeding water saturation.

\subsubsection{Particle size considerations}

It should be noted that aside from the effects of the equipment used to pass the ash into the IMCA/ZINC, the ash was not size selected. The peak in the number distribution of the particles was at approximately $1 \mu \mathrm{m}$, however, a range of diameters were present. This makes quantitative comparison between the mineral dust and ash in Fig. 7 difficult, however larger particles tend to be better nuclei, therefore if anything, the quality of the ash as a deposition ice nucleus, in comparison with mineral dust particles, is even poorer than suggested by Fig. 7 .

A comparison with measurements made at $220-224 \mathrm{~K}$ by Moehler et al. (2006), using mineral dusts with lognormal size distributions and mode diameters of $0.3 \mu \mathrm{m}$ to $0.5 \mu \mathrm{m}$, shows that the volcanic ash studied here proves to be a more efficient deposition IN than these sizes of Asian dust and Saharan dust particles, but leads to ice formation at similar saturations as the ATD particles.

Interestingly, the volcanic ash particles studied here seem to be rather poor $\mathrm{CCN}$ at cold temperatures. This is suggested by the fact that in the immersion mode experiments, at $238 \mathrm{~K}$, the frozen fraction is ca. $30 \%$, however the activated fraction in the deposition experiments only increases to $0.5 \%$ when water saturation is reached at this temperature. The same holds at $233 \mathrm{~K}$, where nearly all particles immersed in droplets should activate. However, the measurements show an activated fraction of only 10-20\% of the ash particles. The next two sections will shed further light on the atmospheric impacts of these particles.

\subsection{Trajectory analysis}

Air parcel trajectories were used to determine if the ash was likely to be involved in immersion or deposition freezing. Approximately 135000 seven day forward trajectories were calculated based on ECMWF meteorological analyses using the trajectory model LAGRANTO (Wernli and Davies, 1997). The trajectories were initialised every three hours from 15 April 2010 to 30 April 2010, on a three dimen-

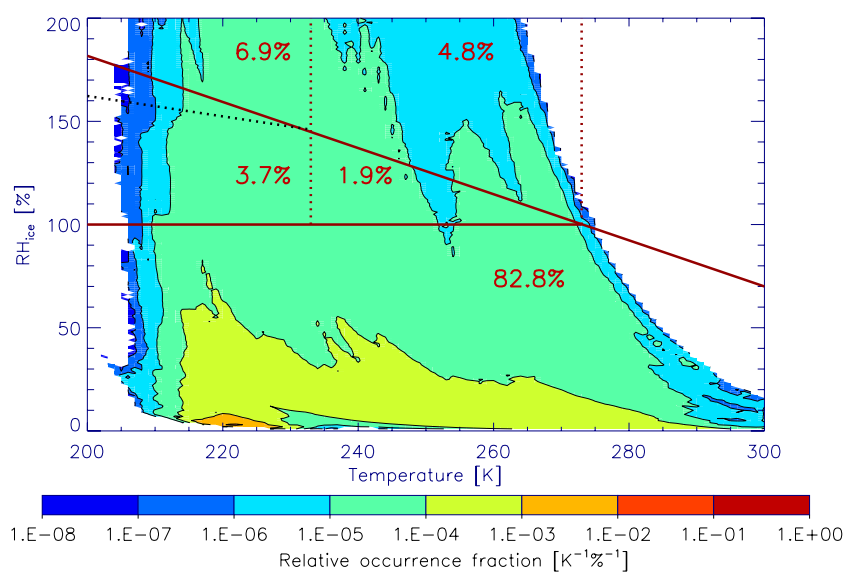

Fig. 8. The fraction of all 90 million trajectory points with a particular $\mathrm{RH}_{\text {ice }}$ and temperature (normalised) from trajectories leaving the Eyjafjallajökull region between 15 and 30 April 2010. $\mathrm{RH}_{\text {ice }}$ at each point is calculated using the water vapour mixing ratio from the initial trajectory point (see text). Red diagonal line: saturation with respect to liquid water $\left(\mathrm{RH}_{\text {liq }}=100 \%\right)$. Red horizontal line: $\mathrm{RH}_{\mathrm{ice}}=100 \%$. Black dashed line: homogeneous ice nucleation (Koop et al., 2000). Red dashed lines (at $T=233 \mathrm{~K}$ and $273 \mathrm{~K}$ ): division lines between warm clouds $(T>273 \mathrm{~K})$, mixed-phase clouds $(233 \mathrm{~K}<T<273 \mathrm{~K})$, and cold cirrus clouds $(T<233 \mathrm{~K})$. The percentage of the trajectory points in each segment surrounded by red lines is indicated by the red numerals. Note: points with $\mathrm{RH}>\mathrm{RH}_{\text {liq }}$ are indicative for condensation of liquid water (i.e. the trajectory will continue along the red diagonal). Compare Wiacek et al. (2010).

sional grid running from $63.13^{\circ} \mathrm{N}$ to $64.13^{\circ} \mathrm{N}$ and $339.4^{\circ} \mathrm{E}$ to $341.4^{\circ} \mathrm{E}$, and spanning 18 pressure levels from $800 \mathrm{hPa}$ to $150 \mathrm{hPa}$. This corresponds approximately to a box with sides of $100 \mathrm{~km}$, centred on the volcano, and extending from an altitude of approximately $2 \mathrm{~km}$ to approximately $14 \mathrm{~km}$. Similar to Wiacek et al. (2010), the water vapour mixing ratio was taken from the analyses at the first trajectory point, and held fixed for the remainder of the trajectory, so that the relative humidity with respect to ice was calculated while avoiding complicating effects from the ECMWF cloud formation algorithm. It should further be noted that any water vapour added to the atmosphere by the eruption is not accounted for. The distribution of the trajectory points is shown in Fig. 8 as a function of temperature and $\mathrm{RH}_{\text {ice. Although the great ma- }}$ jority of the trajectory points are sub-saturated with respect to ice and are not involved in cloud forming processes, approximately $49 \%$ of the trajectories eventually reached ice saturation (approximately $33 \%$ reached water saturation). Approximately $5.6 \%$ of the points are found in the regions between ice and water saturation where heterogeneous nucleation of ice may principally occur, or on the water saturation curve (approximately $11.7 \%$, the points above this line would collapse onto it if water condensation was properly accounted for). 


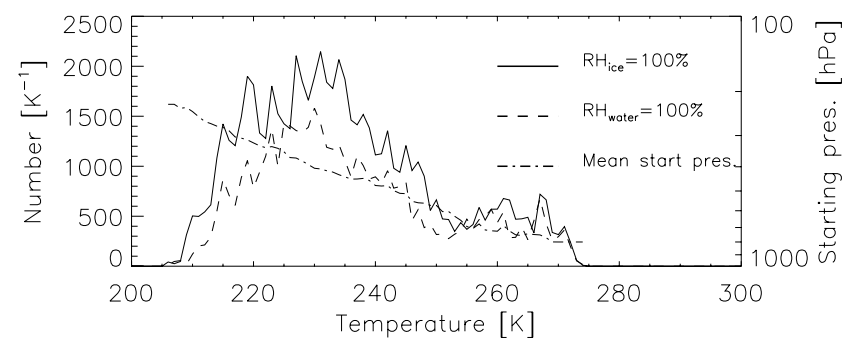

Fig. 9. The number of trajectories reaching ice or water saturation at a particular temperature (dashed and solid lines, respectively), along with the mean starting pressure of the trajectories which reached ice saturation at each temperature (dot dashed line).

The number of trajectories crossing the ice or water saturation line are shown in Fig. 9, as a function of the temperature at which they cross. Only the first crossing point was counted, trajectories which oscillate between super-saturated and sub-saturated conditions are not counted more than once. Of the trajectories reaching ice saturation, almost exactly half did so in the regime of cold cirrus clouds at temperatures below $233 \mathrm{~K}$, where ice nuclei are likely to become active in the deposition mode as $\mathrm{RH}_{\text {ice }}$ increases. The other half reached ice saturation at warmer temperatures in the regime of mixedphase clouds and so-called "warm ice clouds" (Wiacek et al., 2010), where the ash is a relatively poor deposition nucleus. Water saturation was reached by approximately $16 \%$ of the trajectories at temperatures below $233 \mathrm{~K}$ and by approximately $17 \%$ at temperatures of $233 \mathrm{~K}$ and higher. Trajectories reaching water saturation in the warmer temperature range may enable ash to influence the formation of mixedphase clouds and lead to immersion mode nucleation of ice.

The temperature at which ice saturation is reached generally depends on the starting pressure of the trajectories (dotdashed line in Fig. 9). On average, the lower the starting pressure (i.e. the higher the starting altitude), the colder the temperature at which ice (or water) saturation is reached. The average starting pressure of trajectories reaching ice saturation at temperatures below $233 \mathrm{~K}$ is approximately $400 \mathrm{hPa}$ or lower (ca. $6.4 \mathrm{~km}$ altitude and higher). During the initial phase of the eruption of Eyjafjallajökull, the plume height reached altitudes of up to $10 \mathrm{~km}$, however this reduced relatively rapidly to altitudes of $4-6 \mathrm{~km}$ for the remainder of April (Schumann et al., 2011). Therefore, for most of the eruption, the ash would have followed trajectories reaching ice saturation at temperatures above $233 \mathrm{~K}$, and immersion freezing would have been the most likely mechanism by which ash would have been involved in ice formation. Any increased water vapour content of the air due to the eruption would lead to saturation at higher temperatures, making it even less likely that a substantial number of the ash containing trajectories reach deposition freezing conditions.

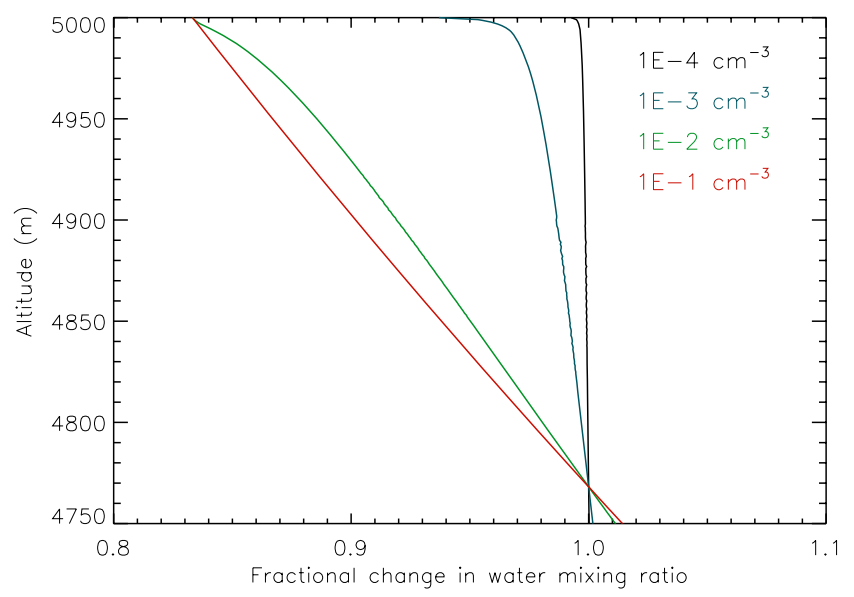

Fig. 10. The fractional dehydration caused by the sedimentation of a $2 \mathrm{~km}$ thick layer of ice coated ash, with number densities of between $1 \times 10^{-4} \mathrm{~cm}^{-3}$ and $1 \times 10^{-1} \mathrm{~cm}^{-3}$. Note that number densities at or above $1 \times 10^{-1} \mathrm{~cm}^{-3}$ lead to total dehydration of the column. Below $4770 \mathrm{~m}$, the column becomes subsaturated, and the sedimenting ice particles begin to evaporate, causing re-hydration.

\subsection{Atmospheric implications}

The injection of volcanic ash into an air parcel may lead to increased dehydration via heterogeneous freezing at higher temperatures and sedimentation of the ice particles. This in turn can lead to reductions in cloud formation in the dehydrated air masses. The importance of this effect depends not only on the efficiency of the ash particles as IN, but on their abundance in comparison with ambient IN. In order to make a conservative estimate of the importance the ash has for atmospheric dehydration, we assume that the ash is the only IN present, and we apply a simple microphysical column model, which assumes that ash-induced ice nucleation has happened at some altitude and then calculates the dehydration (and at lower altitudes, rehydration) caused by the sedimenting ice particles.

The model tracks the sedimentation of a mono-disperse population of ice particles through a column of air, allowing for the growth and evaporation of the particles at the different model layers. The model was initialised with an upper boundary of $5 \mathrm{~km}$ and a temperature of $256.0 \mathrm{~K}$ on the upper model level. Below this level, a vertical resolution of $1 \mathrm{~m}$ was used throughout a $1000 \mathrm{~m}$ layer, and the temperature and pressure were set for each layer assuming a dry adiabatic lapse rate. The whole column was initialised with a water vapour mixing ratio of $3312 \mathrm{ppmv}$, so that at an altitude of $5 \mathrm{~km},(T=256 \mathrm{~K}), \mathrm{RH}_{\text {ice }}$ was approximately $120 \%$.

A $2 \mathrm{~km}$ thick ash layer above the top of the model was assumed, which corresponds to one of the thickest ash layers observed by Schumann et al. (2011). The ash particles were assumed to have an initial infinitesimally thin coating of ice and a diameter of $1 \mu \mathrm{m}$. Various number densities of these 
particles were then allowed to fall through the column. The resulting change in water vapour is plotted in Fig. 10, for ice number densities between $1 \times 10^{-4} \mathrm{~cm}^{-3}$ and $1 \times 10^{-1} \mathrm{~cm}^{-3}$. At the top of the model column, the particles fall slowly, and remain in a layer long enough to take up larger quantities of water from the gas phase. At the top of Fig. 10, the lines converge to a water vapour fraction of approximately 0.83 , which corresponds to a saturation with respect to ice of approximately 1.0. As the particles grow, they sediment faster, depleting the gas phase of the layers they pass through less and less. In addition, the super-saturation decreases with decreasing altitude. At an altitude of approximately $4770 \mathrm{~m}$, the column becomes subsaturated and the ice particles begin to evaporate. Low number densities of particles can quickly reach large sizes and sediment rapidly, however cause little dehydration due to their scarcity. Above number densities of approximately $1 \times 10^{-4} \mathrm{~cm}^{-3}$, a significant dehydration begins to occur. If the ash layer is however only $100 \mathrm{~m}$ thick, for example, significant dehydration begins to occur at number densities above $1 \times 10^{-3} \mathrm{~cm}^{-3}$ (not shown). Very similar results are obtained for a model top altitude of $6 \mathrm{~km}$, temperature of $240 \mathrm{~K}$ and water mixing ratio of $770 \mathrm{ppmv}$ (not shown). As IN numbers increase, the available water vapour is spread over more ice particles and these therefore remain smaller and sediment less rapidly. However even at the highest number densities shown in Fig. 10, the average fall speed of the lower edge of the ash plume which enters the supersaturated column is around $1.2 \mathrm{~km} \mathrm{~h}^{-1}$, therefore dehydration is efficient. The highest number density shown in Fig. 10 leads to complete dehydration of the super saturated part of the column.

For the number densities of the most efficient ash IN shown in Table 2, as observed with the DSC experiments, this means that the atmospheric effects would be negligible. The particles would nucleate ice at comparatively high temperatures, rapidly grow, and sediment without any substantial effect on atmospheric water vapour.

On the other hand, the average ash particles studied in the IMCA/ZINC (Fig. 5) had a size distribution peaking at around $1 \mu \mathrm{m}$, and as shown in Fig. 2, particles below approximately $2 \mu \mathrm{m}$ diameter make up the vast majority of the ash particles. The particle number densities reported by Schumann et al. (2011) attributable to ash range from approximately $1 \mathrm{~cm}^{-3}$ to $20 \mathrm{~cm}^{-3}$, which is by far high enough for the gas phase water to be substantially depleted when these particles nucleate ice. Therefore in the absence of high numbers of better IN, the formation of ice by ash, as shown in Fig. 5, will lead to depletion of the gas phase at temperatures approximately $3-4 \mathrm{~K}$ above those required for homogeneous freezing.

\section{Summary and discussion}

\subsection{Rare, efficient ash IN compared with typical tropospheric IN}

Bulk and single particle measurements show that ash particles from the April-May 2010 eruption of Eyjafjallajökull, Iceland, act as ice nuclei in both the immersion and deposition freezing modes. The bulk measurements exhibit a large variation in the freezing temperature in mixed suspensions, which suggests the presence of very rare, but efficient IN. Both the variation in freezing temperature, as well as the freezing temperature itself decrease when the concentration of the solution is reduced, providing further evidence for the rarity of these most efficient IN. A general dependence of freezing temperature on the surface area of ash in the suspension is found, with larger available surface areas leading to higher freezing temperatures. The highest freezing temperature measured in the DSC for the ash was at ca. $263.5 \mathrm{~K}$, with the median freezing temperature for Ey0 $5 \mathrm{wt} \%$ ash suspension being $258.5 \mathrm{~K}$. For comparison, experiments with a $5 \mathrm{wt} \%$ ATD suspension gave a freezing temperature of approximately $268.0 \mathrm{~K}$. The atmospheric number density of the best IN from the bulk DSC experiments was estimated by scaling the DSC results to atmospheric measurements of the ash plume 1-2 days down wind of the eruption, and was found to be generally low, namely only ca. $3.3 \times 10^{-6} \mathrm{~cm}^{-3}$ to $3.3 \times 10^{-5} \mathrm{~cm}^{-3}$ for particles causing freezing at $251-258 \mathrm{~K}$, when scaled to measurements made over the Skagerrak. Scaling to measurements made over Zurich, Switzerland, led to number densities approximately a factor of 3 higher, those over the Baltic Sea lead to even lower number densities. These values can be compared with measurements of free tropospheric IN concentrations. Typical tropospheric IN concentrations at temperatures warmer than $235 \mathrm{~K}$ were found to range from $10^{-4} \mathrm{~cm}^{-3}$ to $10^{-1} \mathrm{~cm}^{-3}$, with the higher concentrations generally being related to lower temperatures and higher super-saturations (Rogers et al., 1998). Concentrations of more than $1 \mathrm{~cm}^{-3}$ were measured with a continuousflow diffusion chamber (CFDC) by DeMott et al. (2003b) in a mineral dust plume, and DeMott et al. (2003a) report concentrations of between approximately $1 \times 10^{-3} \mathrm{~cm}^{-3}$ to $0.1 \mathrm{~cm}^{-3}$ at temperatures warmer than $238 \mathrm{~K}$, where heterogeneous nucleation is the only possible ice formation mechanism. During the INSPECT-II campaign at Storm Peak in 2004, Richardson et al. (2007) measured IN concentrations of $1 \times 10^{-3} \mathrm{~cm}^{-3}$ to $1 \times 10^{-2} \mathrm{~cm}^{-3}$ active at temperatures from $223 \mathrm{~K}$ to $258 \mathrm{~K}$, which should be representative of the ambient free troposphere. IN concentrations of between approximately $1 \times 10^{-4} \mathrm{~cm}^{-3}$ and $1 \times 10^{-2} \mathrm{~cm}^{-3}$ are presented in DeMott et al. (2010), for temperatures between approximately $250 \mathrm{~K}$ and $265 \mathrm{~K}$. Although they show a few measurements of IN concentrations as low as $1 \times 10^{-5} \mathrm{~cm}^{-3}$ at temperatures around $243 \mathrm{~K}$, generally the IN concentrations 
between $238 \mathrm{~K}$ and $250 \mathrm{~K}$ lie in the range $1 \times 10^{-3} \mathrm{~cm}^{-3}$ to $1 \times 10^{-1} \mathrm{~cm}^{-3}$.

Therefore, within 1-2 days transport time from the eruption plume, the estimated concentrations of ash particles active as IN in the temperature range $>251 \mathrm{~K}$ are smaller than the lower end of the ambient IN concentrations, for all locations considered in Table 2. Calculations performed with a microphysical column model show that number densities of IN below approximately $1 \times 10^{-4} \mathrm{~cm}^{-3}$ for an ash layer thickness of approximately $2 \mathrm{~km}$ do not lead to a significant dehydration of the atmosphere, and even higher ash number densities are needed to cause dehydration if the ash cloud is thinner.

Interestingly, Bingemer et al. (2011) find the highest IN concentrations in their $2 \mathrm{yr}$ daily measurement time series, near Frankfurt, during the Eyjafjallajökull eruption $\left(0.05 \mathrm{~cm}^{-3}\right.$ to $0.25 \mathrm{~cm}^{-3}$ with a peak over $\left.0.6 \mathrm{~cm}^{-3}\right)$. Their measurements were made at temperatures between $255 \mathrm{~K}$ and $265 \mathrm{~K}$, and suggest that the volcanic ash from the Eyjafjallajökull eruption indeed contains a much higher number of IN active in this temperature range than estimated from our DSC experiments. The number densities reported by Bingemer et al. (2011) also contrast with our deposition mode experiments carried out at $248 \mathrm{~K}$, which show no IN activity below water saturation, and an active IN concentration of $3 \times 10^{-4} \mathrm{~cm}^{-3}$ above water saturation. Using accumulation mode number densities of the non-volatile aerosol fraction in the range of $1-5 \mathrm{~cm}^{-3}$, as reported by Schumann et al. (2011), our IN concentrations measured during the deposition mode experiments translate to an active IN concentration of only $3 \times 10^{-2} \mathrm{~cm}^{-3}-1.5 \times 10^{-3} \mathrm{~cm}^{-3}$. There is therefore a clear difference between the IN concentrations reported by Bingemer et al. (2011) and those presented here.

Part of the sample 15.04.10-2b (which we refer to as EY0 here), was also obtained by Steinke et al. (2011), who investigated its IN properties in the AIDA (Aerosol Interaction and Dynamics in the Atmosphere) cloud chamber. They find an onset of immersion freezing (a frozen fraction of $0.1 \%$ ) at $249 \mathrm{~K}$, and a frozen fraction of $2 \%$ at $245 \mathrm{~K}$. These measurements are interesting because they fit in the blind range of temperatures between our DSC and IMCA/ZINC measurements. Below $240 \mathrm{~K}$, Steinke et al. (2011) observed only deposition freezing, whereas the IMCA/ZINC measurements show a rapid increase in the frozen fraction, due to immersion freezing, as temperature decreases between $240 \mathrm{~K}$ and $236 \mathrm{~K}$. As discussed above, in the IMCA/ZINC immersion freezing measurements, frozen fractions below approximately $10 \%$ cannot be detected, therefore it is not possible to directly compare our immersion freezing measurements with those of Steinke et al. (2011). However, our deposition mode measurements are comparable with theirs, and produce extremely similar frozen fractions as a function of $\mathrm{RH}_{\text {ice }}$.

\subsection{Average ash IN compared with typical tropospheric IN}

The immersion mode experiments, which were carried out with IMCA/ZINC, provide data on the average IN, expressed as the frozen fraction of particles as a function of temperature, in contrast to the DSC experiments, which are only sensitive to the best IN in a sample. The IMCA/ZINC experiments show that average ash particles cause a ca. 3-4 K increase in the ice nucleation temperature with respect to homogeneous freezing of cloud droplets produced by $\mathrm{CCN}$ activation of ammonium sulphate particles. Due to the large number densities of ash particles in the volcanic plume, at plume ages of a few days or less, the heterogeneous ice nucleation at 3-4 $\mathrm{K}$ above the homogeneous freezing temperature may substantially deplete the gas phase water.

The ZINC deposition freezing experiments show that at temperatures above the homogeneous freezing threshold of pure water, the volcanic ash is a much poorer deposition IN compared with mineral dusts. For temperatures of $228 \mathrm{~K}$ and $223 \mathrm{~K}$, the frozen fraction reaches almost its maximum value at $\mathrm{RH}_{\text {ice }}=120 \%$. At these low temperatures, the volcanic ash indeed turns into a deposition mode IN with efficiencies comparable to the ones of mineral dusts.

The accumulation and coarse mode particle number densities measured by Schumann et al. (2011), in the ash plume over the Skagerrak and the Baltic Sea came to around $1 \mathrm{~cm}^{-3}$, therefore if this ash plume had encountered temperatures lower than $238 \mathrm{~K}$, the deposition mode experiments would suggest an IN concentration of between $1.0 \times 10^{-3} \mathrm{~cm}^{-3}$ and $0.1 \mathrm{~cm}^{-3}$, which is comparable to measurements of free tropospheric IN concentrations.

An analysis of seven day forward air parcel trajectories from the site of the eruption shows that for the longest period of the eruption when the ash ejected to heights below 4-6 km, ash would mostly have encountered ice, and water saturation at relatively warm temperatures (above $233 \mathrm{~K}$ ). Therefore, for the greatest part of this particular eruption, immersion freezing would have been the dominant influence of the ash. Further, it is likely that as the ash plume aged, the particles obtained a coating of sulphuric acid and water. This would further suppress deposition freezing (Cziczo et al., 2009; Chernoff and Bertram, 2010; Sullivan et al., 2010).

In summary, while we find evidence for efficient IN among the ash particles, 1-2 days down wind of the eruption they were not present in concentrations high enough to have an impact on atmospheric water vapour or cloud formation. Conversely, average IN, leading to freezing 3-4 K above temperatures required for homogeneous nucleation were likely present in high number concentrations a few days down wind of the eruption, and could have led to modifications of cloud formation, such as an advanced onset of glaciation, slightly reduced optical depths of the resulting ice clouds, and dehydration. Immersion freezing would have been the most likely mechanism for this ice nucleation. 
Acknowledgements. C. R. H. was partly funded by SNSF grant number 200021_120175/1. B. Z. thanks the European Commission through the EC Integrated Project RECONCILE (226365-FP7ENV-2008-1). V. P. acknowledges support by NCCR Climate. We would like to thank Felix Lüönd for his valuable contribution during discussions. We would like to thank Barbara Pietragalla of MeteoSchweiz for the pictures of ash particles in the pollen sampler, used in Fig. 1, as well as for the useful discussions relating to these pictures.

Edited by: W. Birmili

\section{References}

Bingemer, H., Klein, H., Ebert, M., Haunold, W., Bundke, U., Herrmann, T., Kandler, K., Müller-Ebert, D., Weinbruch, S., Judt, A., Ardon-Dryer, K., Levin, Z., and Curtius, J.: Atmospheric ice nuclei in the Eyjafjallajökull volcanic ash plume, Atmos. Chem. Phys. Discuss., 11, 2733-2748, doi:10.5194/acpd11-2733-2011, 2011.

Bukowiecki, N., Zieger, P., Weingartner, E., Jurányi, Z., Gysel, M., Neininger, B., Schneider, B., Hueglin, C., Ulrich, A., Wichser, A., Henne, S., Brunner, D., Kaegi, R., Schwikowski, M., Tobler, L., Wienhold, F. G., Engel, I., Buchmann, B., Peter, T., and Baltensperger, U.: Ground-based and airborne in-situ measurements of the Eyjafjallajökull volcanic aerosol plume in Switzerland in spring 2010, Atmos. Chem. Phys. Discuss., 11, 12949-13002, doi:10.5194/acpd-11-129492011, 2011.

Chernoff, D. I. and Bertram, A. K.: Effects of sulfate coatings on the ice nucleation properties of a biological ice nucleus and several types of minerals, J. Geophys. Res., 115, D20205, doi:10.1029/2010JD014254, 2010.

Cziczo, D. J., Froyd, K. D., Gallavardin, S. J., Moehler, O., Benz, S., Saathoff, H., and Murphy, D. M.: Deactivation of ice nuclei due to atmospherically relevant surface coatings, Environ. Res. Lett., 4, 044013, doi:10.1088/1748-9326/4/4/044013, 2009.

Dellino, P., Isaia, R., La Volpe, L., and Orsi, G.: Statistical analysis of textural data from complex pyroclastic sequences: implications for fragmentation processes of the Agnano Monte Spina Tephra (4.1 ka), Phlegraean Fields, Southern Italy, B. Volcanol., 63, 443-461, 2001.

DeMott, P., Cziczo, D., Prenni, A., Murphy, D., Kreidenweis, S., Thomson, D., Borys, R., and Rogers, D.: Measurements of the concentration and composition of nuclei for cirrus formation, P. Natl. Acad. Sci. USA, 100, 14655-14660, doi:10.1073/pnas.2532677100, 2003a.

DeMott, P., Sassen, K., Poellot, M., Baumgardner, D., Rogers, D., Brooks, S., Prenni, A., and Kreidenweis, S.: African dust aerosols as atmospheric ice nuclei, Geophys. Res. Lett., 30, 1732, doi:10.1029/2003GL017410, 2003b.

DeMott, P. J., Prenni, A. J., Liu, X., Kreidenweis, S. M., Petters, M. D., Twohy, C. H., Richardson, M. S., Eidhammer, T., and Rogers, D. C.: Predicting global atmospheric ice nuclei distributions and their impacts on climate, P. Natl. Acad. Sci. USA, 107, 11217-11222, doi:10.1073/pnas.0910818107, 2010.

Durant, A. J., Shaw, R. A., Rose, W. I., Mi, Y., and Ernst, G. G. J.: Ice nucleation and overseeding of ice in volcanic clouds, J. Geophys. Res., 113, D09206, doi:10.1029/2007JD009064, 2008.
Earle, M. E., Kuhn, T., Khalizov, A. F., and Sloan, J. J.: Volume nucleation rates for homogeneous freezing in supercooled water microdroplets: results from a combined experimental and modelling approach, Atmos. Chem. Phys., 10, 7945-7961, doi:10.5194/acp-10-7945-2010, 2010.

Fornea, A. P., Brooks, S. D., Dooley, J. B., and Saha, A.: Heterogeneous freezing of ice on atmospheric aerosols containing ash, soot, and soil, J. Geophys. Res., 114, D13201, doi:10.1029/2009JD011958, 2009.

Heiken, G. and Wohletz, K.: Volcanic Ash, University of California Press, Berkley, 246 pp., 1985.

Hussain, K. and Saunders, C.: Ice nucleus measurement with a continuous-flow chamber, Q. J. Roy. Meteorol. Soc., 110, 75-84, 1984.

Isono, K., Komabayasi, M., and Ono, A.: Volcanoes as a source of atmospheric ice nuclei, Nature, 183, 317-318, 1959.

Koop, T., Luo, B., Tsias, A., and Peter, T.: Water activity as the determinant for homogeneous ice nucleation in aqueous solutions, Nature, 406, 611-614, 2000.

Langer, G., Garcia, C., Mendonca, B., Pueschel, R., and Fullerton, C.: Hawaiian volcanos - source of ice nuclei, J. Geophys. Res., 79, 873-875, 1974.

Lüönd, F., Stetzer, O., Welti, A., and Lohmann, U.: Experimental study on the ice nucleation ability of size-selected kaolinite particles in the immersion mode, J. Geophys. Res., 115, D14201, doi:10.1029/2009JD012959, 2010.

Marcolli, C., Gedamke, S., Peter, T., and Zobrist, B.: Efficiency of immersion mode ice nucleation on surrogates of mineral dust, Atmos. Chem. Phys., 7, 5081-5091, doi:10.5194/acp-7-50812007, 2007.

Möhler, O., Field, P. R., Connolly, P., Benz, S., Saathoff, H., Schnaiter, M., Wagner, R., Cotton, R., Krämer, M., Mangold, A., and Heymsfield, A. J.: Efficiency of the deposition mode ice nucleation on mineral dust particles, Atmos. Chem. Phys., 6, 30073021, doi:10.5194/acp-6-3007-2006, 2006.

Nicolet, M., Stetzer, O., Lüönd, F., Möhler, O., and Lohmann, U.: Single ice crystal measurements during nucleation experiments with the depolarization detector IODE, Atmos. Chem. Phys., 10, 313-325, doi:10.5194/acp-10-313-2010, 2010.

Prenni, A. J., Demott, P. J., Rogers, D. C., Kreidenweis, S. M., Mcfarquhar, G. M., Zhang, G., and Poellot, M. R.: Ice nuclei characteristics from M-PACE and their relation to ice formation in clouds, Tellus B, 61, 436-448, doi:10.1111/j.16000889.2009.00415.x, 2009.

Richardson, M. S., DeMott, P. J., Kreidenweis, S. M., Cziczo, D. J., Dunlea, E. J., Jimenez, J. L., Thomson, D. S., Ashbaugh, L. L., Borys, R. D., Westphal, D. L., Casuccio, G. S., and Lersch, T. L.: Measurements of heterogeneous ice nuclei in the Western United States in springtime and their relation to aerosol characteristics, J. Geophys. Res., 112, D02209, doi:10.1029/2006JD007500, 2007.

Rogers, D., DeMott, P., Kreidenweis, S., and Chen, Y.: Measurements of ice nucleating aerosols during SUCCESS, Geophys. Res. Lett., 25, 1383-1386, 1998.

Schnell, R. and Delany, A.: Airborne ice nuclei near an active volcano, Nature, 264, 535-536, 1976.

Schnell, R. C., Pueschel, R., and Wellman, D.: Ice nucleus characteristics of Mount St-Helens effluents, J. Geophys. Res., 87, 1109-1112, 1982. 
Schumann, U., Weinzierl, B., Reitebuch, O., Schlager, H., Minikin, A., Forster, C., Baumann, R., Sailer, T., Graf, K., Mannstein, H., Voigt, C., Rahm, S., Simmet, R., Scheibe, M., Lichtenstern, M., Stock, P., Rüba, H., Schäuble, D., Tafferner, A., Rautenhaus, M., Gerz, T., Ziereis, H., Krautstrunk, M., Mallaun, C., Gayet, J.-F., Lieke, K., Kandler, K., Ebert, M., Weinbruch, S., Stohl, A., Gasteiger, J., Groß, S., Freudenthaler, V., Wiegner, M., Ansmann, A., Tesche, M., Olafsson, H., and Sturm, K.: Airborne observations of the Eyjafjalla volcano ash cloud over Europe during air space closure in April and May 2010, Atmos. Chem. Phys., 11, 2245-2279, doi:10.5194/acp-112245-2011, 2011.

Seifert, P., Ansmann, A., Gro, S., Freudenthaler, V., Heinold, B., Hiebsch, A., Mattis, I., Schmidt, J., Schnell, F., Tesche, M., Wandinger, U., and Wiegner, M.: Ice formation in ashinflueuenced clouds after the eruption of the Eyjafjallajökull volcano in April 2010, J. Geophys. Res., in press, 2011.

Seinfeld, J. H. and Pandis, S. N.: Atmospheric Chemistry and Physics from air pollution to climate change, second edition, John Wiley \& Sons, Inc., Hoboken, New Jersey, USA, 2006.

Shaw, R., Durant, A., and Mi, Y.: Heterogeneous surface crystallization observed in undercooled water, J. Phys. Chem. B, 109, 9865-9868, doi:10.1021/jp0506336, 2005.

Steinke, I., Mhler, O., Kiselev, A., Niemand, M., Saathoff, H., Schnaiter, M., Skrotzki, J., Hoose, C., and Leisner, T.: Ice nucleation properties of fine ash particles from the Eyjafjallajökull eruption in April 2010, Atmos. Chem. Phys. Discuss., 11, 17665-17698, doi:10.5194/acpd-11-17665-2011, 2011.

Stetzer, O., Baschek, B., Lueoeond, F., and Lohmann, U.: The Zurich Ice Nucleation Chamber (ZINC) - a new instrument to investigate atmospheric ice formation, Aerosol Sci. Tech., 42, 64-74, doi:10.1080/02786820701787944, 2008.

Sullivan, R. C., Petters, M. D., DeMott, P. J., Kreidenweis, S. M., Wex, H., Niedermeier, D., Hartmann, S., Clauss, T., Stratmann, F., Reitz, P., Schneider, J., and Sierau, B.: Irreversible loss of ice nucleation active sites in mineral dust particles caused by sulphuric acid condensation, Atmos. Chem. Phys., 10, 1147111487, doi:10.5194/acp-10-11471-2010, 2010.
Welti, A., Lüönd, F., Stetzer, O., and Lohmann, U.: Influence of particle size on the ice nucleating ability of mineral dusts, Atmos. Chem. Phys., 9, 6705-6715, doi:10.5194/acp-9-6705-2009, 2009.

Wernli, H. and Davies, H.: A Lagrangian-based analysis of extratropical cyclones 1 . The method and some applications, Q. J. Roy. Meteorol. Soc., 123, 467-489, 1997.

Wiacek, A., Peter, T., and Lohmann, U.: The potential influence of Asian and African mineral dust on ice, mixed-phase and liquid water clouds, Atmos. Chem. Phys., 10, 8649-8667, doi:10.5194/acp-10-8649-2010, 2010.

Wienhold, F.: Measurements and analysis of the Eyjafjallajköull plume optical properties over Switzerland in April 2010, Atmos. Chem. Phys. Discuss., submitted, 2011.

Zimanowski, B., Büttner, R., Lorenz, V., and Häfele, H.: Fragmentation of basaltic melt in the course of explosive volcanism, J. Geophys. Res., 102, 803-814 1997.

Zobrist, B., Marcolli, C., Koop, T., Luo, B. P., Murphy, D. M., Lohmann, U., Zardini, A. A., Krieger, U. K., Corti, T., Cziczo, D. J., Fueglistaler, S., Hudson, P. K., Thomson, D. S., and Peter, T.: Oxalic acid as a heterogeneous ice nucleus in the upper troposphere and its indirect aerosol effect, Atmos. Chem. Phys., 6, 3115-3129, doi:10.5194/acp-6-3115-2006, 2006.

Zobrist, B., Koop, T., Luo, B. P., Marcolli, C., and Peter, T.: Heterogeneous ice nucleation rate coefficient of water droplets coated by a nonadecanol monolayer, J. Phys. Chem. C, 111, 2149-2155, doi:10.1021/jp066080w, 2007.

Zobrist, B., Marcolli, C., Pedernera, D. A., and Koop, T.: Do atmospheric aerosols form glasses?, Atmos. Chem. Phys., 8, 52215244, doi:10.5194/acp-8-5221-2008, 2008. 